\title{
A AUTORREPRESENTAÇÃO COMO UM NOVO OBJETO MUSEOLÓGICO - O CASO DOS CURADORES BORORO NO MUSEU DE HISTÓRIA DO PANTANAL
}

\author{
ARAMIS LUIS SILVA ${ }^{1}$ \\ CEBRAP/UNIFESP, BRASIL
}

\begin{abstract}
RESUMO: Este texto propõe reenquadrar a "autorrepresentação" a partir de uma nova perspectiva: como um novo objeto de representação do campo museológico, isto é, um metaobjeto de formas socialmente reconheciveis, derivado de uma especifica tecnologia social, cuja lógica de operação e efeitos práticos dos seus possíveis modos de uso ainda reclamam por investigações mais detalhadas. Isso será feito por meio da análise da participação dos curadores bororo da aldeia de Meruri, do Mato Grosso, vinculados ao Museu das Culturas Dom Bosco, da Missão Salesiana, no processo de formação do Museu de História do Pantanal (Muhpah), da cidade de Corumbá, Mato Grosso do Sul. A partir de parcerias colaborativas situadas e contextualmente estabelecidas, foi essa rede que produziu o diorama instalado na seção etnológica da instituição que passou a representar localmente não só "a cultura bororo", como também a "autorrepresentação bororo".
\end{abstract}

PALAVRAS-CHAVE: Autorrepresentação, Bororo, Curadoria indígena, Museologia

ABSTRACT: This text proposes to reframing "self-representation" from a new perspective: as a new object of representation of the museological field, that is, a meta-object of socially recognizable forms, derived from a specific social technology, whose logic of operation and effects of their possible modes of use still demand more detailed investigations. This will be done by analyzing the participation of Bororo curators from the village of Meruri, in Mato Grosso, linked to the Museum of Cultures Dom Bosco, of the Salesian Mission, in the process of forming the Pantanal History Museum (Muhpah) in the city of Corumbá, Mato Grosso do Sul. Based on situated and contextually established collaborative partnerships, it was this network that produced the diorama installed in the institution's ethnological session, which started to not only represent "Bororo culture" locally, but also "Bororo self-representation".

KEYWORDS: Self-representation, Bororo, Indigenous curatorship, Museology

\footnotetext{
${ }^{1}$ Jornalista e cientista social com mestrado e doutorado em Antropologia Social pela Universidade de São Paulo. Atualmente é pós-doc da Unifesp (Ciências Sociais), colaborador do Centro Brasileiro de Análise e Planejamento e pesquisador do Grupo de Estudo sobre Religião e Esfera Pública, do Laboratório de Estudos sobre Diferenciação e Interseccionalidade, do Grupo de Estudo da Mediação e Alteridade e do Laboratório Interdisciplinar, Ciências Sociais e Saúde. E-mail: aramisluis@uol.com.br
} 


\section{Introdução}

Reconhecendo a centralidade da categoria "autorrepresentação" no interior das novas teorias e práticas museológicas que colocam em xeque as formas de representação do "outro" alicerçadas no modelo de objetivação colonial, esta apresentação propõe um deslocamento da forma de abordá-la. Sem colocar em suspeita seu valor heurístico para a construção de novas práticas que vêm modelando os trabalhos colaborativos desenvolvidos com a participação de representantes de populações em processo de representação coletiva e profissionais que se especializam nesta tecnologia de visibilidade de identidades, pretende-se aqui analisar a autorrepresentação partir de uma nova perspectiva: como um novo objeto de representação do campo museológico, isto é, um meta-objeto de formas socialmente reconhecíveis, derivado de uma específica tecnologia social, cuja lógica de operação e efeitos práticos dos seus possíveis modos de uso ainda reclamam por investigações mais detalhadas.

Ou seja, além de poder ser compreendida como um poderoso mecanismo de produção de novos discursos representacionais executados por sujeitos historicamente destituídos dessa prerrogativa, a autorrepresentação, quando viabilizada por redes de alianças entre diversos agentes e ancorada em torno da compatibilização de interesses múltiplos, também pode ser encarada como um derivado simbólico de processos de mediação socioculturais que se traduzem em cenas públicas que precisam ser analisadas para além dos conteúdos culturais que elas veiculam. Afinal, se essas cenas, por um lado, abrem, sim, espaço para narrativas de agentes que entram na disputa pela redefinição dos imaginários sociais em bases de políticas simbólicas mais ampliadas, elas também têm o potencial de chancelar, deliberada ou não intencionalmente, toda a engenharia social das redes que a colocam em curso na forma de um discurso muitas vezes não percebido como polifônico.

Essas "cenas da autorrepresentação", geralmente vinculadas a agendas de instituições, organizações e coletivos, passíveis de registros etnográficos e/ou jornalísticos, e inclusive circulantes por diversas mídias, como as eletrônicas, adquirem valor semântico em uma dimensão diferente do primeiro objeto da autorrepresentação (os cantos, as danças, os ritos, etc.). Tornando-se um meta-objeto, as cenas da autorrepresentação passam a funcionar tais quais as molduras tradicionais das criações pictóricas: elas não podem competir explicitamente com o objeto que subliminarmente está aceito no primeiro plano da representação intencional e deliberadamente; contudo, são as cenas da autorrepresentação que Ihes dão as suas margens de sentido, envolvendo o objeto da representação em uma instância particular que Ihe confere autenticidade e legitimação.

Assim, da perspectiva deste texto, a autorrepresentação será abordada enquanto um efeito de comunicação, passível de ser replicado por diversas redes sociológicas e de resultados reconhecíveis, capaz de 
imprimir sentidos éticos e políticos sobre os mais diversos objetos representacionais. Em síntese, trata-se de uma tecnologia social em ação, materializada na forma de cenas produtoras de sentidos construídos a partir dos circuitos que promovem suas aparições e circulação pública.

Para demonstrar essa possível forma de enquadrar a categoria, este artigo, em diálogo situado com a literatura antropológica interessada sobre o tema, se valerá do exame de processos representacionais, bem como das disputas de sentido a eles associados, que transcorrem desde as primeiras décadas deste século a partir da aldeia dos índios Bororo de Meruri, no estado do Mato Grosso².

Fundada em 1902 em torno do projeto missionário dos padres salesianos sobre uma área cuja territorialidade bororo a ultrapassa no tempo e no espaço, a Aldeia Meruri, reconhecida pela literatura acadêmica como um campo privilegiado para análises de processos de comunicação interculturais, tornou-se um interessante palco para observarmos como a museologia, amparada pelos seus aparelhos conceituais e dispositivos materiais concretos, vem se constituindo nos últimos anos como uma matriz discursiva capaz de reorganizar os quadros que dão inteligibilidade a uma relação espelhada de longa data entre missionários e a população indígena bororo missionada, como já havia postulado Novaes (1993).

Nesta longa relação histórica, marcada por complexos sistemas de dominações e alianças que se reatualizam e sobrepõem constantemente, indígenas e sua dita "cultura" e padres e sua dita "religião" se definem e são definidos a partir dos meios ou constrangimentos de que cada uma dessas partes dispõe e experimenta para poder participar do processo de definir e representar quem são os Bororo para um público situado para fora dessa relação. Esse argumento ganha contornos mais delineados quando nos lembramos das aparições públicas e espetaculares do começo do século XX direcionadas à veiculação das missões salesianas e dos seus "projetos civilizatórios" abordadas por Novaes (1993), e, mais especificamente, das etnografias e exposições missionárias produzidas ao longo do processo de missionação, tratadas, respectivamente, por Montero (2012) e Silva (2018).

Foge do escopo deste texto recuperar a longa história que interrelaciona freiras e padres missionários vinculados à Missão Salesiana do Mato Grosso e mulheres e homens bororo da aldeia de Meruri, atualmente organizados em cerca de 65 famílias. Os sucessivos capítulos que se sucedem desde antes da fundação da missão na região dos Tachos no início do século $X X$ e reconfiguram continuamente as condições e os modos de permanência da missão entre essa população indígena até os dias de hoje vêm sendo reiteradamente analisados e reanalisados por pesquisadores vinculados aos mais diversos campos disciplinares (c,

\footnotetext{
${ }^{2}$ Ao pé do morro que lhe deu o nome, Meruri está instalada na Terra Indígena homônima, em área de 82.031 hectares que se prolonga entre os municípios de General Carneiro e Barra do Garças (MT). Além de Meruri, - aldeia adjacente à Missão Sagrado Coração de Jesus, com mais de 650 moradores -, existiam até 2015 outras aldeias menores na terra indígena: Garças, a segunda maior e mais antiga, Nabureau e Koge Kureu.

SILVA, Aramis Luis. A autorrepresentação como um novo objeto para a representação museológica - o caso dos curadores Bororo no Museu de História do Pantanal. Espaço Ameríndio, Porto Alegre, v. 14, n. 1, p. 49-67, jan./jul. 2020.
} 
1987 e 2001; Viertler, 1990 e 1991; Novaes, 1993 e 1999; Vangelista, 1999; De Castilho, 2000; Tacca, 2002; Ribeiro, 2005; Nakata, 2008; Montero, 2012; Silva, 2009 e 2018). A despeito das várias abordagens teóricas e enquadramentos metodológicos que ressaltaram variados aspectos dessa trajetória de conflitos, disputas e acordos, interessa saber que os autores convergem ao demonstrar, cada um ao seu modo, que esse específico processo de missionação é inseparável de engenharias de nomeação e classificação de populações, que sempre estiveram vinculadas, em associação/subordinação ${ }^{3}$ ou confronto/atrito ${ }^{4}$, com sistemas de governamentalidade mais amplos, inscrevendo a missão e seu campo de relações em projetos políticos modelados para além do estrito universo missionário.

É justamente essa perspectiva que nos estimula a enquadrar Meruri como um campo de forças que pode ser mais bem descrito da perspectiva das redes, levando-nos para além do restritivo par dicotômico "Bororo" $x$ "brancos" comumente acionado pela literatura. Até mesmo porque, se de fato seguirmos à risca o pressuposto de que a mola-mestra desse sistema de relações gira em torno das engenharias de nomeação e classificação historicamente postas em curso na aldeia, precisaremos considerar que formulações comunitaristas e/ou etnicizantes ali circulantes são, em vez de traduções transparentes de um real, produções dessa maquinaria representacional operada a muitas mãos e a partir de múltiplas posições sociais, geográficas e institucionais, incluindo neste tópico a própria antropologia.

Dito isso, torna-se evidente uma relação em cadeia que organiza novos horizontes analíticos para reenquadrarmos os processos representacionais de Meruri: para entender o histórico processo missionário da aldeia, que inter-relaciona agentes vinculados a diferentes repertórios simbólicos, é imprescindível observar como essa estrutura relacional diferenciadora e orientada à gestão das diferenças foi e continua sendo publicamente representada para fora da aldeia. E se as macroidentidades referentes às partes que compõem esse sistema de relações ("Bororo" e "salesianos"), bem como as categorias que thes dão sentido ("cultura/tradição" e "salvação/religião", por exemplo), são definidas e redefinidas neste mesmo processo de representação pública dessa relação, as análises não devem se restringir aos conteúdos representados, como os elementos da cultura material, cantos, ritos e demais elementos que metaforizam formas culturais (ou as objetivam nos termos wagnerianos). Isto é, partindo desses conteúdos, cabem aos analistas responder outras perguntas: quais são as configurações de rede que produzem contextualmente esses conteúdos representacionais e em

\footnotetext{
${ }^{3}$ Como no projeto de assentamento local das populações até então nômades e de subalternização deste contingente populacional no mercado de trabalho rural mato-grossense. Ver Viertler, 1990 e 1991.

${ }^{4}$ Como na participação decisiva na luta pelo reconhecimento legal da Terra Indígena, marcada pelo assassinato do Padre Rodolfo Lunkenbein em 1976 pelos posseiros que contestavam o processo de demarcação. A terra foi demarcada em 1976, mas somente em 11 de fevereiro de 1987, que, com a pressão da Igreja Católica, os 82 mil hectares de Meruri foram definitivamente homologados pelo Decreto Presidencial $n^{\circ}$. 94.014. Sobre esse momento da história de Meruri, ver especialmente Ochoa (1995).

SILVA, Aramis Luis. A autorrepresentação como um novo objeto para a representação museológica - o caso dos curadores Bororo no Museu de História do Pantanal. Espaço Ameríndio, Porto Alegre, v. 14, n. 1, p. 49-67, jan./jul. 2020.
} 
quais circunstâncias? Quais são as específicas maquinarias para colocar essas representações em circulação social cada vez mais ampliada e quais são as matrizes discursivas que a elas dão inteligibilidade e legitimidade? Enfim, quais são os seus efeitos práticos?

Dois grandes projetos culturais iniciados nos anos 2000 na aldeia confirmaram a pertinência deste reenquadramento, evidenciando que no palco etnográfico merurense contemporâneo a língua do patrimônio material e imaterial se tornou franca, passando a costurar velhos acordos ou velhos conflitos estabelecidos entre missionários e homens e mulheres Bororo e a dar sentidos a novos projetos capazes de vocalizá-los (acordos e conflitos). Tais iniciativas culturais, é importante ressaltar, acabaram por dinamizar a secular rede de relações merurense, daqui para frente entendida como um sistema que articula em longa duração a população bororo local e os operadores da missão salesiana. Neste caso, abriram as portas para entrar em cena os agentes museológicos, que estavam até fora do campo missionário. Esse movimento, como veremos a seguir, foi decisivo para reatualizar a estrutura relacional de Meruri.

O primeiro projeto, que não vingou devido à morte prematura do seu idealizador, era uma aldeia-museu que ficaria aberta à visitação de turistas interessados em uma experiência cultural "conhecer in loco a cultura bororo"), capitaneado por essa liderança indígena e pequena porção da sua parentela, apoiados por organização não governamental indígena e pelo Ministério da Cultura, então sob gestão do ministro Gilberto Gil. Essa nova aldeia-museu, batizada de Meri Ore Eda (em português, a Morada dos Filhos do Sol), seria levantada na mesma terra indígena, mas existiria a quilômetros de distância da velha aldeia construída em torno da missão, em sinal de oposição ao projeto salesiano. $O$ idealizador desta iniciativa cultural, que também pretendia recuperar aquilo que havia sido descrito por ele como a "verdadeira religião bororo", planejava construir uma aldeia sustentável e alternativa à Meruri, chamada por ele de "vila de padres". A meta era "salvar a cultura bororo" da "descaracterização" ou até mesmo da "extinção" e o turismo foi aventado como uma das possíveis formas de renda, tornando assim a "cultura bororo" em um capital cultural a ser economicamente explorado.

O segundo projeto, também descrito na chave da "revitalização cultural" e ainda em curso, veio por meio da instalação de um centro dedicado à preservação da memória da técnica da cultura material bororo. Isto é feito por meio da formação e gestão de acervo de peças produzidas em oficinas culturais didáticas e da salvaguarda da coleção de artefatos históricos bororo repatriada em 2001 do museu salesiano da Itália, o Museo Etnológico Missionário Colle Don Bosco. As peças haviam sido enviadas para a Europa no contexto, principalmente, da realização das grandes exposições missionárias de 1925 e 1926, respectivamente no Vaticano, organizada pela Santa Sé, e em Turim, pela Missão Salesiana. Instalado no complexo arquitetônico da Missão do Sagrado Coração de Jesus de Meruri e criado a partir da parceria entre missionários,

\footnotetext{
${ }^{5}$ Sobre o projeto de construção de Meri Ore Eda, ver Silva (2009).

SILVA, Aramis Luis. A autorrepresentação como um novo objeto para a representação museológica - o caso dos curadores Bororo no Museu de História do Pantanal. Espaço Ameríndio, Porto Alegre, v. 14, n. 1, p. 49-67, jan./jul. 2020.
} 
acadêmicos laicos, grupo de professores da escola indígena e grande parte dos demais moradores indígenas de Meruri, esse projeto consagrou-se em 2006 como o grande vencedor do Prêmio Cultura Viva, iniciativa lançada pelo mesmo ministério apoiador da primeira iniciativa local que se configurou como um projeto local concorrente ${ }^{6}$.

Esses dois projetos merurenses, suas redes sociais marcadas por distintos modos de agenciamentos e suas lógicas de interações e distribuição de poder já foram apresentados nos trabalhos acima citados (Silva, 2009 e 2018). Contudo, até então não havia sido explicitado e analisado um específico fenômeno que este campo de relações organizado em torno de disputas de narrativas representacionais nos permite observar: a autorrepresentação, para além de ser uma prática museológica que tem o potencial de subverter as posições de sujeito/objeto em contextos de reorganização de poderes das instituições especializadas em produção e veiculação de representação (Ames, 1999), pode se desdobrar em outro plano em uma performance politicamente produtiva, capaz de modelar um novo objeto de representação social: a autorrepresentação como um meta-objeto de forma social reconhecível, com função simbólica subliminar e sentidos definidos em razão das suas contextuais e específicas formas de uso prático. É este caráter plástico desse meta-objeto que lhe confere um trunfo a ser considerado: a rede que for socialmente reconhecida como capaz de executar a "autorrepresentação" em nome de uma dita comunidade será aquela capaz de outorgar o seu projeto cultural e político, obtendo a prerrogativa pública de representar uma cultura, um grupo ou um povo.

A seguir, vamos analisar a autorrepresentação a partir desta perspectiva, retomando um capítulo específico da história do segundo projeto cultural de Meruri: a participação dos curadores bororo do centro de cultura na montagem do Museu de História do Pantanal (Muhpah), inaugurado em agosto de 2008 em Corumbá, Mato Grosso do Sul. As informações sobre a instituição e alguns dados sobre a participação dos curadores bororo foram colhidas em textos jornalísticos, sites de turismo, páginas institucionais vinculadas ao Muhpah $^{7}$ e artigo acadêmico que examina o projeto educativo do museu e as tratativas relacionas às questões indígenas (Da Silva e Gonçalves, 2018). Material fotográfico registrando o trabalho dos curadores também foi consultado no arquivo do Museu das Culturas Dom Bosco, em pesquisa realizada na instituição em $2015^{8}$. Vídeos disponíveis no YouTube também nos servem de janelas para nos aproximar desse museu, descrito como a primeira instituição

\footnotetext{
${ }^{6}$ Sobre o processo de formação e funcionamento do centro de cultura, originalmente intitulado Centro de Cultura Pe. Rodolfo Lunkenbein, em homenagem ao diretor da missão assassinado em 1976, ver Silva (2018).

${ }^{7}$ Disponível em http://museumuhpan.blogspot.com/ ou https://muhpan.wordpress.com. Acesso em $20 \mathrm{de}$ outubro de 2019.

${ }^{8}$ Os materiais fotográficos não puderam ser publicados, pois, de acordo com a atual direção da instituição, o museu está em fase de redefinição dos protocolos de uso das imagens. Contatos com a direção solicitando autorização foram realizados no dia 28 de outubro de 2019.

SILVA, Aramis Luis. A autorrepresentação como um novo objeto para a representação museológica - o caso dos curadores Bororo no Museu de História do Pantanal. Espaço Ameríndio, Porto Alegre, v. 14, n. 1, p. 49-67, jan./jul. 2020.
} 
museológica da região pantaneira, centro de divulgação de conhecimento científico e ponto aglutinador de memória popular ${ }^{9}$.

\section{A representação Bororo no Pantanal}

“Em funcionamento desde 2008, o Museu de História do Pantanal (Muhpan) foi criado para atender à necessidade de contar um pouco da história natural e guardar a cultura presente no bioma pantaneiro", assim começa o texto do jornalista Thiago Andrade, anunciando no dia 15 de março de 2015 que o museu histórico de Corumbá, cidade sul-matogrossense às margens do Rio Paraguai, seria alvo de uma grande reforma, a primeira da sua ainda breve história ${ }^{10}$.

O jornalista repete uma formulação encontrada em praticamente todos os materiais dedicados a apresentar a instituição e que dará o enquadramento para explicar a presença dos Bororo no museu: o Muhpan foi instituído com o objetivo de ajudar a contar a história da ocupação humana na região pantaneira. "Em 2000, com o Pantanal sendo decretado pela Unesco como reserva da biosfera, o Ministério da Cultura (MinC) entendeu que a região merecia sediar um museu, o que também aumentaria o potencial turístico" ${ }^{11}$, acrescenta o repórter, destacando que a iniciativa começou a ganhar "forma nas mãos do arqueólogo Carlos Alberto Etchevarne, doutor pelo Museu Nacional de História Natural de Paris"12. Etchevarne assinou o projeto museológico do Muhpan.

Encampada pela Fundação Barbosa Rodrigues (FBR) e endossada pela Secretaria de Turismo e Meio Ambiente de Corumbá, a ideia do novo museu foi apresentada ao Minc e inscrita no Monumenta, programa de recuperação de imóveis privados em centros históricos, desenvolvido pelo Instituto do Patrimônio Histórico e Artístico Nacional (Iphan) ${ }^{13}$. Por meio da Lei de Incentivo à Cultura e com recursos oriundos da Petrobras e do Instituto Votorantim, sua construção foi iniciada em 2004, dando nova função social ao Edifício Comercial Wanderley, Baís \& Cia, uma edificação histórica, datada de 1876. Além de abrigar um dos principais armazéns do Porto Geral de Corumbá, o prédio sediou durante anos uma agência do Banco do Brasil.

O projeto museográfico foi assinado por Nivaldo Vitorino, museólogo, urbanista, arquiteto e ambientalista paulista que veio a falecer em 2018. A ideia geral, realizada a partir da combinação de peças, painéis fotográficos, pinturas figurativas, vídeos, recursos sonoros e diversos tipos de dioramas, foi transformar o museu em um portal para uma viagem sensorial pelo ambiente pantaneiro, abrangendo " 8 mil anos

\footnotetext{
${ }^{9}$ Ver por exemplo https://www.youtube.com/watch?v=1k8CMUh_XN8.

10 Texto disponível na íntegra em https:/www.correiodoestado.com.br/arte-e-cultura/museu-de-historiado-pantanal-em-corumba-sera-reformado/299948/. Acesso, 20 de outubro de 2019.

${ }^{11}$ Idem.

12 Idem.

${ }^{13}$ Sobre o Programa Monumenta, ver

http://portal.iphan.gov.br/uploads/publicacao/ColReg_RecuperacaoImoveisPrivadosCentrosHistoricos m. pdf. Acesso 19 de outubro de 2019.

SILVA, Aramis Luis. A autorrepresentação como um novo objeto para a representação museológica - o caso dos curadores Bororo no Museu de História do Pantanal. Espaço Ameríndio, Porto Alegre, v. 14, n. 1, p. 49-67, jan./jul. 2020.
} 
de história da ocupação humana na região"14. Esse mesmo texto informa que além dos conteúdos ligados à arqueologia, etnologia, etno-história, história e antropologia, o museu "preenche diversas outras funções junto à comunidade com o objetivo de envolvê-la nas questões da preservação e valorização cultural do lugar"15.

Em 2009, no ano seguinte à inauguração do Muhpan, o trabalho realizado no museu rendeu a Vitorino o prêmio Rodrigo Melo Franco de Andrade, concedido pelo Iphan. O caso foi inscrito com um nome sugestivo: "Em busca do acervo perdido", fazendo referência ao modo de Vitorino solucionar um dos maiores problemas para a formação das coleções do novo museu do pantanal: a escassez de peças e coleções para compor o seu acervo.

Texto publicado em setembro de 2007 pelo Iphan conta que Vitorino havia comparado a formação do acervo com a montagem de um grande quebra-cabeça, uma vez que, segundo ele, as peças que poderiam ir para esse museu estariam espalhadas por instituições do Rio de Janeiro, São Paulo, Rio Grande do Sul, Portugal, Espanha e Rússia. De acordo com Vitorino, só a montagem desse jogo de encaixes tridimensionais garantiria que toda a história da região pudesse ser contada a partir em único espaço. Com o museu montado, o público conheceria "os processos históricos que forjaram a identidade pantaneira" e poderia "'encontrar-se' no seu presente", ressaltou ele, no mesmo texto publicado pelo Iphan ${ }^{16}$.

A garimpagem empreendida por Vitorino em várias partes da região pantaneira e arquivos situados para além da região teria sido reforçada com a doação para o acervo nascente, via Universidade Federal do Mato Grosso do Sul, de peças coletadas pelos arqueólogos Gilson Martins e José Luis Peixoto, informam os sites. Contudo, uma parceria firmada com o Museu das Culturas Dom Bosco, o museu de Campo Grande administrado pela Missão Salesiana de Mato Grosso, instituição que já havia naquela época se tornado mantenedora daquele mesmo Centro de Cultura Bororo de Meruri, teria garantido, além de peças etnológicas bororo, um elemento que conferiria ao circuito expositivo um caráter especial: a autorrepresentação desse grupo indígena.

Da Silva e Gonçalves (2018), embasadas pela leitura do relatório museológico escrito por Etchervarne, contam-nos que o circuito expositivo do museu possui 24 subtemas tratados em 24 salas separadas, sendo que seis versam especificamente sobre a temática indígena. Na sala Etnologia, espaço reservado para fazer referência aos grupos indígenas que seriam os mais representativos durante os primeiros anos de contato entre as populações autóctones pantaneiras e as frentes de expansão colonial $^{17}$, os visitantes encontram um conjunto de artefatos que

\footnotetext{
${ }^{14}$ Informação em página vinculada ao Muhpan, disponível em https://muhpan.wordpress.com/. Acesso em 20 de outubro de 2019.

${ }^{15} \mathrm{Idem}$. O texto não faz referência às coleções paleontológicas.

16 Texto disponível em http://portal.iphan.gov.br/noticias/detalhes/1917/novo-museu-em-corumbacontara-a-historia-do-pantanal. Acesso em 20 de outubro de 2019.

${ }^{17} \mathrm{O}$ museu inscreve em um painel os nomes dos Bororo, Payaguás, Kinikinawa, Guató, Orejones, Xarayes, Caiapó, Kadiwéu e Guarani.

SILVA, Aramis Luis. A autorrepresentação como um novo objeto para a representação museológica - o caso dos curadores Bororo no Museu de História do Pantanal. Espaço Ameríndio, Porto Alegre, v. 14, n. 1, p. 49-67, jan./jul. 2020.
} 
comporiam a tradicional "vestimenta masculina Bororo" (idem, p. 48). As peças, como um exemplar de pariko, o icônico artefato da arte plumária bororo, um labrete e uma narigueira foram produzidos pelo grupo de Bororo mobilizados pelas oficinas de "revitalização cultural" promovidas pelo Centro de Cultura Bororo de Meruri"1.

As autoras informam ainda que esse espaço expositivo possui também "uma urna funerária que é apresentada como da Tradição Descalvado (...). Em seguida possui um painel com nomes dos seguintes grupos indígenas: Bororo, Payaguás, Kinikinawa, Guató, Orejones, Xarayes, Caiapó, Kadiwéu e Guarani" (Da Silva e Gonçalves, 2018, p. 47). Mais adiante elas contam que, além dos Bororo, os únicos grupos que ganharam tratativas especiais foram os Guaicuru e Payaguá. "Na Sala Payaguá e Guaicuru há um quadro para cada etnia pintado pelo artista plástico paulista Filipelli e um texto que conta de forma sucinta as práticas dos Guaicuru e os Payaguá" (Idem, p. 48).

Mas é na última sala dedicada à temática indígena desse circuito expositivo que a representação "dos Bororo" ganha um destaque especial. Nessa operação, eles são iconizados na forma de uma entidade étnica representada pelo museu como se ela estivesse fora da história, como formulam Da Silva e Gonçalves (2018). Porém, como veremos a seguir, tratou-se de uma execução museográfica assinada pelos "próprios Bororo" dentro do "próprio museu", como é destacado por algumas mídias interessadas em representar a instituição e o seu projeto museológico. Os textos fazem sempre referência ao trabalho executado pelos curadores bororo vinculados ao Museu das Culturas Dom Bosco, administrado pelos padres salesianos, embora essa relação com o museu ou com a missão não seja explicitada.

O texto de Da Silva e Gonçalves, por exemplo, nos informa ainda que nessa sala, denominada Pintura Corporal Bororo, pode ser observado um diorama da família Bororo, que "possui um tamanho semelhante ao de seres humanos, o que dá vida ao espaço" (p. 48). Na sequência, as autoras acrescentam: "as réplicas de indígenas foram confeccionadas de isopor e ornamentadas pelos próprios indígenas Bororo" (idem).

Ou seja, é nesse espaço que os curadores indígenas de Meruri, "que viajaram 1.200 quilômetros até Corumbá" para ajudar a contar a história da ocupação humana do Pantanal, segundo atesta reportagem publicada no jornal O Estado de S. Paulo em outubro de $2007^{19}$, transmutam-se metonimicamente em representantes totais dos Bororo, uma população indígena distribuída entre seis Terras Indígenas demarcadas em áreas descontínuas do Estado do Mato Grosso, ${ }^{20}$ espalhadas por diferentes

\footnotetext{
${ }^{18}$ A informação foi gentilmente confirmada pela direção do Museu das Culturas Dom Bosco, por meio de mensagens trocadas no dia 29 de outubro de 2019.

19 Texto disponível na íntegra em https://viagem.estadao.com.br/noticias/geral,museu-em-corumbamostra-alma-pantaneira,65549. Acesso em 20 de outubro de 2019.

${ }^{20}$ Além da Terra Indígena de Meruri, estão registradas e homologadas as TIs Perigara, Sangradouro/Volta Grande (onde também existe uma missão salesiana) e Tadarimana. A TI Teresa Cristina está sob júdice, uma vez que sua reserva foi declarada em revisão em 2005. Jarudore, apesar de reconhecida como área reservada, foi invadida, e foi construída dentro dela um vilarejo. Segundo informa o Conselho Indigenista Missionário em julho deste ano, o juízo da Subseção Judiciária de Rondonópolis, no dia 28 de junho, SILVA, Aramis Luis. A autorrepresentação como um novo objeto para a representação museológica - o caso dos curadores Bororo no Museu de História do Pantanal. Espaço Ameríndio, Porto Alegre, v. 14, n. 1, p. 49-67, jan./jul. 2020.
} 
biomas. Assim, apesar de morarem no cerrado, na Bacia do Rio Araguaia, os curadores de Meruri passaram a representar a identidade pantaneira dos seus "parentes" de Perigara, a única aldeia bororo hoje remanescente nessa região, na confluência dos Rios São Lourenço e Corixo do Bebê. Vale considerar que a escolha da dupla se deu por conta, isto é, para além do reconhecimento público da sua origem bororo, fator consciente da escolha, das expertises e repertórios específicos que ela porta, em parte, por integrar uma rede museológica que os ajudou a se construírem socialmente como curadores indígenas.

O resultado final do trabalho dos curadores bororo foi uma obra dupla ${ }^{21}$. No centro da representação plástica está a "família bororo" composta por cinco bonecos de isopor em tamanho natural. Um casal de pé, formado por um homem robusto de braços cruzados, um leve passo à frente da mulher, mais baixa, que pousa serenamente sua mão sobre seu ombro, encostando um dos seios desnudos de isopor em seu braço. A mulher fica amparada apenas em cima de uma das pernas. A outra fica dobrada em forma de gancho e apoiada sobre a primeira, imprimindo movimento à cena e selando a imagem do homem enquanto um esteio. Eles parecem que olham para uma criança deitada ao chão, com os cotovelos ao solo e as mãos segurando a cabeça. Bem próxima à criança, outra mulher de aspecto sereno. Ela está sentada de pernas cruzadas e sugestivamente em interação com a criança. Completa a cena outro homem. Ele, também de pé e altivo, parece que está se aproximando da cena. A sensação é efeito da gestualidade impressa por uma sugestão de movimento, criado por uma grande lança que ele porta. Todos estão em uma floresta, representada ao fundo por uma pintura cheia de palmeiras e buritis, em tons quentes avermelhados e amarelados que combinam com as pinturas clânicas que revestem os corpos dos bonecos com a indianidade bororo.

Mas, ali, no museu de Corumbá, o que emoldura e atribui sentidos a essa representação da "família bororo" é "a autorrepresentação bororo", reconhecida e anunciada pelos textos interessados em esmiuçar o projeto museológico local. Num mesmo ato, a autorrepresentação bororo dá credibilidade e legitimidade à obra e ao museu. No caso da instituição, ela serve de prova da sua abertura para reconhecer a autoria indígena e da sua disposição, em linha com as políticas museológicas contemporâneas, para redistribuir a autoridade do saber-fazer museal.

Porém, o que estamos aqui sugerindo é que a autorrepresentação deve ser analisada para além desta perspectiva, daqui para frente, considerada como êmica. A autorrepresentação, neste caso etnográfico, assim como em qualquer outro, precisa ser lida como a materialização de

reconheceu "o direito dos índios Bororos à posse e usufruto da TI Jarudore, num total de 4.706 hectares, e determinou a desocupação da área pelos não índios que exploram atividade econômica na terra indígena no prazo máximo de 90 dias. A sentença não abrange a sede urbana do distrito de Jarudore. Texto na íntegra está disponível em https://cimi.org.br/2019/07/justica-reconhece-direito-de-indigenas-da-etnia-bororo-aposse-sobre-a-ti-jarudore-em-mato-grosso/. Acesso em 25 de outubro de 2019.

${ }^{21}$ A descrição e análise foi realizada a partir das fotografias registradas durante o processo de produção do diorama, arquivadas no acervo do Museu das Culturas Dom Bosco, Mato Grosso do Sul. 
uma tecnologia de comunicação que não existe sem a rede que lhe dá suporte e disputa por meio de ações práticas os seus sentidos. Ou seja, foram, sim, os curadores que decidiram sobre qual clã pertenceria cada um dos bonecos, definindo também a plasticidade de cada elemento iconizado a fim de representar em 3D o que foi objetivado como sendo "a família bororo". Foram eles também, em diálogo direto com Vitorino, que puseram a mão na massa para executar a representação bororo no museu, como atesta a documentação visual consultada no arquivo do Museu das Culturas Dom Bosco de Campo Grande. Mas essa moldura (autorrepresentação) só ganha contornos mais bem definidos quando se sabe que a atuação dos curadores integra um circuito de alianças institucionais mais abrangente, seladas com a participação de outros representantes do staff não indígena do museu salesiano.

E levando a análise para um plano mais complexo, essa cena da autorrepresentação posta em curso no museu de Corumbá ganha outro nível de inteligibilidade quando se descobre que o time para garantir o trabalho da autorrepresentação era ainda composto por um videomaker bororo e um fotógrafo não indígena, ambos vinculados ao Museu Dom Bosco e incumbidos de capturar, em cascata (o fotógrafo registrou o videomaker gravando o trabalho dos curadores), a autorrepresentação bororo no museu como um objeto metalinguístico e transmidiático.

\section{Os curadores indígenas na rede}

No processo de formação do Centro de Cultura Bororo de Meruri, instituição museal inaugurada na aldeia em 2001 e mais tarde autoproclamado e reconhecido publicamente como um museu comunitário, dois agentes indígenas vinculados a uma rede mais ampla de apoiadores locais foram alçados à função de curadores indígenas. Escolhidos em função do engajamento e colaboração diferenciada com o projeto implementado por uma rede de acadêmicos em aliança com os missionários, os saberes desses agentes indígenas acerca dos repertórios bororo foram fundamentais para garantir esta nova posição e solidificar laços firmados com essa rede ${ }^{22}$.

A curadora, do clã Apiborege (da metade exogâmica Tugarege), nascida em 1964, era, à época, nora de um dos moradores mais velhos de Meruri e considerado memória viva da "tradição bororo" local. O curador, do clã Iwagudu (também Tugarege), nascido no mesmo ano que a curadora, era filho de um dos chefes de Tadarimana, aldeia bororo cuja parcela populacional havia se mudado para Meruri na década de 70 , transferência que foi responsável, por exemplo, pela alavancagem do uso da língua bororo na aldeia, até então majoritariamente dominada pelo português.

\footnotetext{
${ }^{22}$ Para saber mais sobre essa complexa rede de relações sociais de Meruri e o seu envolvimento nos projetos museais locais, ver Silva 2009 e 2018.

SILVA, Aramis Luis. A autorrepresentação como um novo objeto para a representação museológica - o caso dos curadores Bororo no Museu de História do Pantanal. Espaço Ameríndio, Porto Alegre, v. 14, n. 1, p. 49-67, jan./jul. 2020.
} 
O processo de formação dessa dupla de curadores, patrocinado pelo centro de cultura de Meruri e envolvendo cursos e oficinais realizados para além da aldeia e em parceria com outras instituições ${ }^{23}$, espelha também o gradativo processo de amadurecimento museológico de toda a rede merurense (missionários e missionados), incrementada a partir de então pelos acadêmicos que estavam até esse momento fora do campo missionário. Na forma de pesquisadores, eles haviam chegado à aldeia para a execução dos seus projetos de doutorado e outros, mais tarde, de mestrado, e captaram ali a oportunidade de desdobrá-los em ações de intervenção social conectadas à ideia de, inicialmente, "resgate cultural", e mais tarde, "revitalização cultural". Dali em diante, em uma estratégica parceria que interessava a quase todos, indígenas, religiosos e acadêmicos aprenderam a fazer na prática um museu comunitário que foi alvo em 2006 de reconhecimento governamental ${ }^{24}$. Esse processo, que deu visibilidade ao projeto merurense, culminou na anexação do projeto e de parte do seu staff à estrutura organizacional da missão salesiana.

Os acadêmicos, que desempenhavam papéis de liderança dentro dessa rede, foram alocados na estrutura organizacional do Museu das Culturas Dom Bosco, que também passou a abrigar institucionalmente o Centro de Cultura de Meruri, e/ou no corpo docente da universidade salesiana, a Universidade Dom Bosco, também localizada na capital sulmato-grossense. Neste processo, o museu foi integrado à universidade, na alçada da reitoria de extensão universitária. Os dois indígenas foram designados para a curadoria do centro de cultura e, a partir de então, pagos para ocuparem essa função, que se desdobrou em atividades revezadas em turnos (a curadora pela manhã e o curador à tarde), como a abertura e fechamento do centro, eventuais reparos em peças danificadas por conta empréstimos para uso e representação do centro dentro e fora da aldeia ${ }^{25}$. Entre as suas principais funcionalidades, além da salvaguarda das coleções, o centro serve também como um laboratório didático para a escola indígena de Meruri, dispondo ainda de um centro de multimídia com vídeos e fotografias produzidas pelos Bororo e recursos úteis para os estudantes como computadores.

Do ponto de vista institucional e teológico salesiano, nada mais coerente em uma construção de rede como essa, uma vez que o projeto posto em curso em Meruri a partir dessa nova aliança foi capaz de reatualizar em novos termos o projeto salvacionista missionário, sempre articulado em torno de projetos pedagógicos (vale lembrarmo-nos da importância dada para as oficinas didáticas do centro de cultura e das suas programações conectadas à escola indígena de Meruri, também instalada no complexo arquitetônico da Missão Salesiana). No que diz

\footnotetext{
${ }^{23}$ Parte desse processo de formação tornou-se alvo de reflexão acadêmica de alguns dos próprios intelectuais envolvidos no processo. Ver, por exemplo, Carvalho, Silva e Braga, 2004.

${ }^{24}$ Sobre o Prêmio Cultura Viva e participação dos agentes museais de Meruri, ver especialmente o capítulo etnográfico publicado em livro (Silva, 2018).

${ }^{25}$ Esse canal de comunicação revelou-se especialmente útil para organizar partes do acervo que são usadas em funerais tradicionais na vizinha Aldeia Garça ou nas celebrações religiosas lideradas pelos salesianos, por exemplo.

SILVA, Aramis Luis. A autorrepresentação como um novo objeto para a representação museológica - o caso dos curadores Bororo no Museu de História do Pantanal. Espaço Ameríndio, Porto Alegre, v. 14, n. 1, p. 49-67, jan./jul. 2020.
} 
respeito às relações envolvendo os curadores indígenas e os acadêmicos, despontam elementos como o compadrio e períodos de coabitação, relacionados a transferências temporárias para Campo Grande, sinalizando que relações também foram construídas fora do âmbito da missão.

Assim, em função de específicas configurações de aliança, acadêmicos, a partir de então vinculados à missão mediante contrato de trabalho, e curadores indígenas, igualmente postos na folha de pagamento da mesma instituição religiosa, e outros moradores da aldeia que engrossaram as fileiras do projeto, passaram a circular pelo Brasil e países como Itália, França, Estados Unidos para exibir em exposições museológicas o poderio de uma tecnologia social operada a muitas mãos capaz de "revitalizar uma tradição cultural", assim como passam a formular esses agentes, acadêmicos, indígenas e religiosos. Ou seja, mais que coleções de artefatos indígenas fabricadas nas oficinas do centro de cultura para serem expostas em outros museus e espaços de cultura, a rede de Meruri passou a exibir, para os circuitos museológicos em que foi inserida, a sua forma de produzir coleções: ensinar técnicas tradicionais de produção de artefatos como um meio didático para rememorar seus antigos contextos de uso. Revitalizar técnicas para revitalizar cultura e revitalizar cultura para revitalizar espiritualidades.

É dessa perspectiva que deve ser encarada a parceria estabelecida entre o nascente Museu Histórico do Pantanal (Muhpan) e a complexa rede museal merurense, socialmente materializada pelo centro cultural, que circula por redes de relações sociais cada vez mais extensas por conta da sua capacidade de representar um povo. Ou seja, trata-se de mais um capítulo do processo de estabelecimento de conexões desse centro cultural que funciona como nó de rede a conectar o sistema social merurense (população bororo e missão), agora revitalizado com a participação de acadêmicos capazes de dar novo sentido ao projeto missionário a partir de uma língua museológica na qual todos estão aprendendo juntos a praticá-la ao fazer novas coleções e novos museus.

Dessa forma, ao bater à porta do Museu das Culturas Dom Bosco de Campo Grande em busca de coleções que representariam pela metonímia uma população e um fragmento humano do pantanal (mesmo que Meruri não esteja referida a esse bioma), o Muhpan encontrou muito mais que uma instituição estritamente especializada na salvaguarda de patrimônios; ele se deparou com um museu, que, ao se conectar à experiência posta em curso pela nova rede merurense (moradores bororo, missionários e acadêmicos), também estava se conectando ao ideário da autorrepresentação, ali, já operando como um novo capital museológico.

É importante lembrar, por exemplo, que o primeiro nome oficial do centro cultural de Meruri foi Centro de Cultura Pe. Rodolfo Lunkenbein, em uma homenagem ao diretor da missão assassinado em 1976 em meio à luta pela demarcação da terra indígena. Mas, à medida que essa instituição foi se conectando a outros agentes e instituições de um campo museológico mais amplo, e absorvendo novas práticas, códigos e discursos para organizá-los, sua nomenclatura para apresentação pública 
também foi remodelado: centro de cultura, centro de memória e museu comunitário de Meruri.

A partir desse ponto de vista, é possível compreender a posição polivalente que os curadores ocupam em um sistema de representações que se desdobra em looping em torno da identidade bororo. Eles, os representantes encarnados dos Bororo, passaram a representar também o centro, que, por sua vez, aos olhos de quem está fora dessa rede, representaria os Bororo enquanto uma coletividade em forma abstrata que daria à dupla o seu sentido social e museal. Assim, vinculados a esse sistema, os curadores tornam-se os elementos-chave para a constituição da autorrepresentação bororo, que, a reboque, ainda conferem legitimidade ao espaço museal de Meruri. Tudo isso, traduzido na forma de cenas passíveis de narração para outros públicos que estão para além do museu, condição que nos dá pistas para entender porque o processo de autorrepresentação posto em curso em Corumbá foi registrado por fotógrafo não bororo vinculado ao Museu das Culturas Dom Bosco e pelo videomarker bororo. Isto é, além de praticada como um exercício de produção textual museográfica, a autorrepresentação é algo para a ser visto como uma cena apreensível, narrável e exemplar.

De fato, os curadores indígenas foram levados ao museu de Corumbá para, a partir dos seus saberes, deixar impresso nos bonecos de isopor do diorama exemplos de pinturas faciais clânicas bororo. Todavia, o valor dessa produção não reside simplesmente nos traços dedilhados à tinta sobre as superfícies de isopor que simulam formas humanas. Elas são pistas de um ato museal maior: os curadores, ao serem capazes de encarnarem o nome Bororo, são aqueles que podem impregnar as peças com a aura da autenticidade cultural. Materializada na forma de uma cena que a oculta, a rede de agentes museológicos multiplica esse mito museal, o Museu Histórico do Pantanal o outorga e o campo museológico corre o risco de perder a nitidez de análise se apostar na autorrepresentação como uma categoria por si só capaz de reinventar novos quadros de pureza.

\section{Considerações finais}

Emergindo como uma resposta alternativa à crise da representação em que o dito ocidente mergulhou e foi captada pela sensibilidade de autores que a trabalharam da perspectiva museológica, como Clifford (1995 e 1997), Ames (1992), L’Estoile (2007) e Porto (2008), apenas para citar alguns dos mais eloquentes, a autorrepresentação sem sombra de dúvida funciona como conceito-chave que organiza com eficiência a crítica às relações históricas de dominações entre grupos populacionais tornadas espetaculares pela linguagem museu, como já postulou Roca (2015). Ou seja, certamente museus e suas velhas maquinarias de comunicação monológicas serviram, sim, como tecnologias de dominação e de legitimação de sistemas de nomeação e classificação opressivos, como bem apontou Asad (1973). 
Todavia, a virada pós-colonialista, que há décadas vem inspirando os contornos de uma Nova Museologia, já postulou um novo lugar para os sujeitos ou coletivos subalternizados pelos processos coloniais poderem falar sobre suas histórias e identidades, que seguem em contínua recriação. É esse movimento que está implícito, de um lado, no florescimento dos novíssimos museus indígenas, e do outro, na modelagem de trabalhos colaborativos que aproximam cada vez mais, e em diversos contextos de relações, populações, como as indígenas, e os especialistas em tecnologias de representação museal. Certamente são dois caminhos, não necessariamente coincidentes, que reorganizam os novos vetores de força que compõem o campo museológico contemporâneo que se propõe estar na vanguarda. Ambos, a partir de múltiplas formas, transformam a autorrepresentação em um programa de execução prática, mas que precisa ser analisado para além daquilo que os seus próprios artífices dizem sobre ela.

Neste texto, por exemplo, a análise da autorrepresentação bororo no museu de Corumbá nos permitiu achados interessantes. De partida, ela evidenciou como a língua da museologia - comprometida com o ideário da autodeterminação dos grupos em processo de representação (ou autorrepresentação) - também pode resultar em efeitos imprevistos, inclusive ambíguos. No caso em foco, ao mesmo tempo em que os vários agentes usam a língua da museologia para dar forma e publicizar seus planos de autonomia, alguns à revelia (curadores indígenas, acadêmicos e museólogos), outros à reboque (missionários), a transformam em um meio para reatualizar e reafirmar o projeto missionário, que ainda pena para encontrar o equilíbrio entre um novo salvacionismo católico, a efetiva incorporação da ideia de autodeterminação dos povos e a dissolução das antigas estruturas de dependência que marcaram a história dessa relação entre missionados e missionários.

Contudo, a análise do processo museológico envolvendo os curadores indígenas de Meruri não foi feita para nos dar acesso à disputa acerca do bom ou do legítimo discurso museológico, colocando-nos na posição de formuladores ou avaliadores de novas versões discursivas. Pelo contrário. Interessa-nos aqui sugerir que os esforços analíticos sejam direcionados para mapear e codificar como essas disputas estão remodelando e reinventando o campo museológico, que se mostra cada vez mais plural, diverso e, como sempre, ambíguo. Num outro plano, apostando em explorar um possível efeito do exagero dos traços deste processo museológico que põe a nu o caráter de fabricação híbrido das autorrepresentações, a intenção foi construir as bases para uma provocação: em que medida essa forma estruturada de produção e veiculação de discursos assentados nas maquinarias museológicas compartilhadas é tão diferente dos outros processos museológicos que estão fora do universo missionário? Qual a resposta? Ela não será encontrada nos discursos êmicos dos agentes envolvidos nos processo, mas, sim, a partir da análise da lógica dos seus agenciamentos para a construção das suas redes de sentido. 
Foi justamente esse programa de análise que deu a embocadura deste texto: observando a partir deste campo etnográfico, a autorrepresentação, no lugar de ter sido tomada como uma prática objetiva (e objetivante) ancorada em uma plataforma normativa abstrata, foi tratada como um efeito de comunicação de uma rede costurada a partir da compatibilização de diversos interesses, passível de produzir não simplesmente discursos, mas posições sociais capazes de sustentálos a partir de sentidos contextualmente produzidos. É dessa forma que a autorrepresentação foi lida como um meta-objeto alvo de representações museológicas.

Observando o processo museal em curso em Meruri, é possível constatar que a construção desses agentes como novos sujeitos museais é inescapável da condição de dotá-los de uma formação discursiva que estrutura o próprio meio museológico. E Meruri já fala a língua Nova Museologia. Não é à-toa, aliás, que eles foram os primeiros grandes vencedores do Prêmio Cultura Viva, evento que pode ser lido como uma apoteose nacional da Nova Museologia. Porém, muito mais que externalizar uma língua, é preciso interiorizá-la a partir de experiências ancoradas em chão social.

Isto nos possibilita perceber que não existe uma língua museológica em si, desencarnada dos seus modos de uso. Pelo contrário. Existem línguas museológicas que se configuram a partir dos seus específicos contextos de uso frente às conjunturas de redes, por sua vez, modeladas por esses contextos. Dessa forma, se não existe uma língua museológica única, também não existem termos museológicos que podem ser tomados como autoexplicativos e de forma desreferencializada, como autorrepresentação ou trabalho colaborativo. Ao contrário, esses conceitos precisam ser vistos como códigos de comunicação que exigem dos analistas novos deciframentos: como as redes que os colocam em prática disputam os seus modos de emprego e significação?

Ou seja, no caso da autorrepresentação dos Bororo de Meruri, suas criações representacionais, que se materializam em diversas cenas públicas como traduções autorais de sujeitos coletivos próprios, não podem ser compreendidos apenas como um conjunto de conteúdos autônomos. Tais criações, expressamente marcadas pelo paradigma culturalista, precisam ser encaradas antes de tudo como uma relação social entre redes mediadas por cenas sociais, como Debord (1997) nos inspira formular.

Para os indígenas de Meruri, hoje devotos de Nossa Senhora Auxiliadora e Dom Bosco, muitos deles já egressos dos bancos das universidades, às vezes vinculados a famílias dependentes de aposentadorias rurais, talvez o maior desafio diante da temática da autorrepresentação não seja simplesmente comprovar os gradientes da autonomia das suas representações. O problema é de outra ordem. Mesmo que eles saibam que podem assumir cada vez mais o controle dos meios e das formas de apresentar quem eles são - basta ver o rico acervo de vídeos e fotos do centro de cultura -, ainda precisam ter de lidar com 
Espaço Ameríndio

os desejos fetichizados de pureza das audiências para além da aldeia. Os bonecos de isopor de Corumbá, mesmo que pintados pelos curadores indígenas, estão lá para provar. 
Espaço Ameríndio

\section{Referências bibliográficas}

AMES, Michael M. Cannibal Tours and Glass Boxes: The Anthropology of Museums. Vancouver, University of British Columbia Press, 1992.

How to Decorate a House: The Re-negotiation of Cultural Representations at the University of British Columbia Museum of Anthropology. Museum Anthropology, v. 22, n. 3, p. 41-51, 1999.

ASAD, Talal. Anthropology \& the Colonial Encounter. Nova York, Humanities Press, 1973.

BORDIGNON, Mário E. Os Bororo na História do Centro Oeste Brasileiro. Missão Salesiana de Mato Grosso, 1987.

. Róia e baile: Mudança cultural Bororo. UCDB, 2001.

CARVALHO, Aivone; SILVA, Dúlcilia Lúcia de Oliveira; e BRAGA, Gedley Belchior. Perspectivas recentes para curadoria de coleções etnográficas. In: Rev. do Museu de Arqueologia e Etnologia, São Paulo, 14: 279-289, 2004.

CLIFFORD, James. Dilemas de la cultura. Antropología, literatura y arte en la perspectiva posmoderna. Barcelona, Gedisa, 1995.

. Four Northwest Coast Museums: Travel Reflections. In Routes:

Travel and Translation in the Late Twentieth Century. Cambridge, Harvard University Press, pp. 107-146, 1997.

DA SILVA, Ketylen Karyne Santos; GONÇALVES, Josiane Peres. Atividades de ensino realizadas no Museu de História do Pantanal/MUHPAN e questões indígenas. Revista Dynamis, 2018, 23.2: 39-53.

DEBORD, Guy. A sociedade do espectáculo. Rio de Janeiro: Contraponto, 1997.

DE CASTILHO, Maria Augusta. Os índios Bororo e os salesianos na Missão dos Tachos. Editora UCDB, 2000.

DE L'ESTOILE, Benoît. Le Goût des Autres. De l'Exposition coloniale aux A'rts premiers. Paris: Flammarion, 2007.

ETCHEVARne, C. Projeto expográfico do Museu de História do Pantanal. Corumbá: Muhpan, 2004.

MONTERO, Paula. Selvagens, civilizados e autênticos - A produção das diferenças nas monografias salesianas no Brasil. São Paulo: Edusp, 2012

NAKATA, Cinthia. Civilizar e educar: o projeto escolar indígena da Missão Salesiana entre os Bororo de Mato Grosso. Dissertação de mestrado para obtenção do grau de mestre em Antropologia Social. Universidade de São Paulo, São Paulo, 2008. 
NOVAES, Cauby. S. Jogos de espelho: imagens da representação de si através dos outros. São Paulo: EDUSP, 1993.

- A épica salvacionista e as artimanhas da resistência: as missões Salesianas e os Bororo de Mato Grosso. Transformando os deuses: os múltiplos sentidos da conversão entre os povos indígenas no Brasil, 1999.

OCHOA, Gonçalo Camargo. Padre Rodolfo Lukenbein: uma vida pelos índios de Mato Grosso. Campo Grande: Missão Salesiana de Mato Grosso, 1995.

PORTO, Nuno. Modos de objectificação da dominação colonial: o caso do Museu do Dundo, 1940-1970. Fundacion Calouste Gulbenkian, 2009.

RIBEIRO, Francisco de Lima et al. O Centro de Cultura Bororo: a reconstrução das práticas de ensino e aprendizagem. 2005.

ROCA, Andrea. Museus indígenas na Costa Noroeste do Canadá e nos Estados Unidos. Revista de Antropologia, v. 58, n. 2, p. 117-142, 2015.

SILVA, Aramis Luis. Deus e o Bope na terra do sol: culturalismos na história de um processo de mediação. São Paulo: Humanitas, 2009.

Mapa de viagem de uma coleção etnográfica - A aldeia bororo nos museus salesianos e o museu salesiano na aldeia bororo. São Paulo: Alameda Casa Editorial, 2018.

TACCA, Fernando de. 'Rituais e Festas Bororo'. A construção do índio como 'selvaGem’ na Comissão Rondon. Revista de Antropologia, São Paulo, vol.45, no.1, 2002.

VANGELISTA, Chiara. "Missões católicas e políticas tribais na frente de expansão: os Bororo entre o século XX e XIX. Revista de Antropologia, São Paulo, vol. 39, $\mathrm{n}^{\circ}$ 2, 1996, p. 141-164.

VIERTLER, Renate Brigitte. A refeição das almas. Uma interpretação etnológica do funeral dos índios Bororo - Mato Grosso. São Paulo: Hucitec, 1991.

As duras penas. Um histórico das relações entre civilizados e índios Bororo do Mato Grosso. São Paulo: FFLCH/USP, 1990. 